\title{
Involvement of the receptor for advanced glycation-end products (RAGE) in B-amyloid-induced toxic effects in rat cerebromicrovascular endothelial cells cultured in vitro
}

\author{
SILVIA BAIGUERA ${ }^{1}$, LARA FIORAVANZO ${ }^{1}$, CLAUDIO GRANDI $^{2}$, ROSA DI LIDDO ${ }^{2}$, \\ PIER PAOLO PARNIGOTTO ${ }^{2}$ and MARCELLA FOLIN ${ }^{1}$
}

Departments of ${ }^{1}$ Biology and ${ }^{2}$ Pharmaceutical Sciences, University of Padua, I-35121 Padua, Italy

Received December 11, 2008; Accepted February 23, 2009

DOI: 10.3892/ijmm_00000199

\begin{abstract}
To ascertain whether the potential biological effects of $\beta$ amyloid ( $\mathrm{BA}$ ) on the endothelium are partly mediated by the receptor for advanced glycation-end products (RAGE), we performed a series of experiments which analyzed the effects of the $\mathrm{BA}_{(1-42)}$ peptide on in vitro cerebromicrovascular endothelial cells (CECs). Our results suggest that RAGE is directly responsible for $\beta A_{(1-42)}$ actions on CECs, such as its toxic effect on cell survival, viability and angiogenic capability. We observed that a 6-h incubation period exposing CECs to $\mathrm{BA}_{(1-42)}$ increased the extracellular levels of nitrite. Furthermore, the presence of a nitric oxide synthase inhibitor, L-NAME, was able to enhance CEC survival and viability. Immunocytochemical analyses demonstrated that the peptide induced expression of the inducible form of NOS, iNOS, typically synthesized in response to immune/inflammatory stimuli. Upon blocking the interaction of $\mathrm{BA}_{(1-42)}$ and RAGE, we observed significantly decreased levels of NO and suppression of iNOS immunoreactivity. In conclusion, our data suggest the involvement of RAGE, at least partly, in mediating the effects of $\mathrm{BA}_{(1-42)}$ on CECs. In particular, the decrease of in vitro cell viability and functionality and nitrosative stress activation was inhibited by blocking $\beta_{(1-42)}$-RAGE interaction.
\end{abstract}

\section{Introduction}

Several studies have demonstrated that Alzheimer disease (AD) is often accompanied by cerebrovascular pathology, structural microvascular abnormalities (such as loss or thinning of endothelium, basement membrane thickening) and

Correspondence to: Professor M. Folin, Department of Biology, University of Padua, Via U. Bassi 58/b, I-35121 Padua, Italy

E-mail: marcella.folin@unipd.it

Key words: B-amyloid, cerebromicrovascular endothelial cells, receptor for advanced glycation-end products, nitrergic system hypoperfusion $(1,2)$, suggesting that vascular deficits might play a causative role in the pathogenic mechanism of AD (3).

$B$ amyloid ( $B A)$, the major component of senile plaque, is considered to have a causal role in the development and progression of $\mathrm{AD}$, and it has been demonstrated that it may accumulate not only in the brain parenchyma but also in the cerebral blood vessels (4). Recent evidence indicates that BA deposited in the brain is linked to $B A$ within the intravascular space, and studies in AD animal models demonstrated that a significant amount of $\mathrm{BA}$ is transported from blood to brain (5). This evidence highlights the importance of the transport of circulating $\mathrm{BA}$ as a source for brain $\mathrm{BA}$ through the bloodbrain barrier $(\mathrm{BBB})$. The peptide concentration within the intravascular space seems, in fact, to be linked to BA deposited in the brain suggesting that peptide transport across the BBB regulates $B A$ brain levels (6). However, BBB does not allow free exchanges of polar solutes, such as $B A$, between blood and brain, due to the presence of a continuous cellular monolayer of tightly junctioned endothelial cells (7). Thus, specialized transporters for the peptide must exist in brain endothelium to shuttle circulating BA into the CNS. Several investigations to identify cellular binding site(s) for $B A$ converged on the receptor for advanced glycation end-products (RAGE) and demonstrated that RAGE seems to mediate BA effects on microglia, BBB and neurons through activating different signaling pathways (8). Moreover, increased RAGE immunoreactivity has been found to be associated with vessels displaying amyloid deposition, and an increase in RAGE expression in affected cerebral vessels has been demonstrated, suggesting the potential involvement of this receptor in the associated perturbation of vascular abnormalities in amyloid-laden vessels (9).

BA-mediated cytotoxicity either in vasculature (10) or in CECs (11) seems to be correlated with oxidative stress and in particular with the involvement of nitrosative stress. There is, in fact, evidence for the involvement of nitric oxide (NO) in the pathological processes of AD (12); increased levels of nitrotyrosine-modified proteins have been found in astrocytes, blood vessels and neuronal cytoplasm in AD (13-15) suggesting that $\mathrm{NO}$ could play a role in the disease process. It has been demonstrated that $\mathrm{BA}$, interacting with neuronal and glial membranes, induced free radical production, with consequent destabilization of cellular membranes $(16,17)$. 
Moreover, $\mathrm{BA}_{(1-42)}$ increased NO levels in microglia and astrocytes by means of inducible nitric oxide synthase (iNOS) activation (18). iNOS is expressed in response to inflammatory stimuli and, producing nanomolar amounts of NO, it is an important mediator of cytotoxicity in the brain (19). Previous studies showed up-regulated expression of iNOS in AD brains and at a cerebral microcirculation level, supporting the hypothesis that aberrant levels of iNOS increase nitrotyrosine levels, which might serve as a marker of oxidative stress in the progression of the neurodegenerative process in AD (15).

Most of these studies have been conducted on neurons, astrocytes and brain parenchyma, and considering the importance of microvasculature disorders in $\mathrm{AD}$, using our in vitro model we studied the effect of $\mathrm{BA}$ on the involvement of RAGE in mediating cytotoxic effects of BA and, in particular, in the activation of the nitrosative system in microvascular endothelial cells. In fact, using rat cerebromicrovascular endothelial cells (CECs) as an in vitro model, we previously found that $\beta_{(1-42)}$ induced CEC death, within a short incubation time, demonstrating peptide toxicity in a time- and concentration-dependent manner (20).

\section{Materials and methods}

Materials. Sprague-Dawley male rats (350-400 g body weight) were purchased from Charles-River (Como, Italy), and the experimental protocol was approved by the local Ethics Committee for Animal Studies. $\beta_{(1-42)}$ was obtained from Calbiochem (Darmstadt, Germany). EC growth medium MV2 was provided by PromoCell (Heidelberg, Germany) and the Nitrate/Nitrite Colorimetric Assay Kit was from Cayman Chemical Co. (Ann Arbor, MI, USA). Mouse antiNOS2 monoclonal IgG antibody and goat anti-RAGE polyclonal IgG were obtained from Santa Cruz (Santa Cruz, CA, USA) and the Peroxidase Substrate Kit DAB was from Vector Laboratories (Burlingame, CA, USA). ECL Advance Western blotting system for chemiluminescence detection was obtained from GE Healthcare (Chalfont St. Giles, UK).

All other chemicals and reagents were purchased from Sigma Chemical Co. (St. Louis, MO).

Sample preparation. Cells at $\sim 80 \%$ confluence were treated with or without either peptide $B \mathrm{~A}_{(1-42)}$, trypsin solution in order to cleavage membrane protein, goat anti-RAGE polyclonal IgG (anti-RAGE) in order to inhibit BA-RAGE binding, or $\mathrm{N}_{\omega}$-nitro-L-arginine methyl ester hydrochloride (L-NAME) in order to inhibit nitric oxide synthase (NOS).

$\mathrm{BA}_{(1-42)}$ was dissolved in double-distilled deionised water at a concentration of $1 \mathrm{mM}$, stored at $-20^{\circ} \mathrm{C}$ and used at the final concentration of $100 \mathrm{nM}$. To remove protein surface interactions, cells were pre-treated with $100 \mathrm{ng} / \mathrm{ml}$ trypsin (9590 units/mg) for $10 \mathrm{~min}$, followed by addition of three molar equivalents of soybean trypsin inhibitor (SBTI 10000 units/ $\mathrm{mg}$ ) for $5 \mathrm{~min}$, then the medium was exchanged and the cells were treated with BA. Anti-RAGE was added to the cultures $30 \mathrm{~min}$ before $B A$ treatment at the concentration of $10 \mathrm{ng} / \mathrm{ml}$. L-NAME was dissolved, just before use, in double-distilled deionised water and added to the medium $(500 \mu \mathrm{M})$ with the BA peptide.
CEC culture and treatment. Rats were decapitated, and the brain was promptly removed. Cerebromicrovascular endothelial cells (CECs) were isolated and cultured according to the method of Abbot et al (21) with few modifications $(20,22)$. CECs from the 3rd and 4th passages were plated on fibronectin-coated Petri dishes and cultured in MV2 medium, as previously described (23). After $24 \mathrm{~h}$ of culture, the medium was replaced with a fresh one containing factors, and CECs were treated for a 6-h incubation period.

Cell survival. To determine the effects of trypsin solution or anti-RAGE pre-treatment on $\mathrm{BA}_{(1-42)}$-induced toxicity, cell survival was evaluated by trypan blue exclusion assay by counting CECs which did not internalize the dye.

Western blotting. At the end of the incubations, cells were harvested in lysis buffer (50 mM Tris- $\mathrm{HCl}, 2 \mathrm{mM}$ EDTA, aprotinin $10 \mu \mathrm{g} / \mathrm{ml}$, leupeptin $10 \mu \mathrm{g} / \mathrm{ml}$, phenylmethylsulfonylfluoride $1 \mathrm{mM}$ ). The protein concentration was measured by using BCA Protein Assay Kit. Total proteins $(30 \mu \mathrm{g})$ were loaded onto $12 \%$ SDS-acrylamide gels. At the end of the run, proteins were transferred to a polyvinyldenefluoride membrane and incubated with goat anti-RAGE polyclonal $\operatorname{IgG}(1: 200,000)$ overnight, and then with the peroxidase-conjugated secondary antibodies for $1 \mathrm{~h}$. Proteins were detected by chemiluminescence.

Cell redox activity. To determine the effects of anti-RAGE pre-treatment on $\mathrm{BA}_{(1-42)}$-induced toxicity, cell redox activity was monitored by the colorimetric MTS assay [3-(4,5dimethylthiazol-2-yl)-5-(3-carboxymethoxyphenyl)-2-(4sulfophenyl)-2H-tetrazolium, inner salt] (CellTiter 96 Aqueous Assay, Promega). Metabolically active cells react with a tetrazolium salt in the MTS reagent to produce a soluble formazan dye that can be observed at a wavelength of $490 \mathrm{~nm}$. After the incubation period, cells were rinsed with PBS (phosphate buffer solution) in order to wash out unattached cells, followed by incubation with $20 \%$ MTS reagent in culture medium for $90 \mathrm{~min}$. Thereafter, aliquots were pipetted into 96-well plates, and the samples were read at $490 \mathrm{~nm}$ in a Microplate Autoreader EL13 (Bio-Tek Instruments, Winooski, VT, USA).

In vitro angiogenesis. Matrigel was thawed on ice overnight, and spread evenly over each well $(50 \mu 1)$ of a 24 -well plate. The plates were incubated for $30 \mathrm{~min}$ at $37^{\circ} \mathrm{C}$ to allow Matrigel to gel. CECs were seeded $\left(2.5 \times 10^{4}\right.$ cells $\left./ \mathrm{cm}^{2}\right)$, pretreated with anti-RAGE and subsequently with the $B A$ peptide. After $24 \mathrm{~h}$ of incubation at $37^{\circ} \mathrm{C}$, cultures were photographed ( 5 fields for each well: the four quadrants and the center) at a magnification of $x 5$. Phase contrast images were recorded using a digital camera (DG 200; Leica Imaging System, Cambridge, UK) connected to a Laborlux S Microscope (Leitz, Wetzlar, Germany) and saved as TIFF files. Image analysis was carried out using the Qwin image analysis software (Leica Imaging System), as previously detailed $(23,24)$, and the following parameters were estimated: percent area covered by CECs, total length of CEC network per field, number of meshes and branching points per fields. 


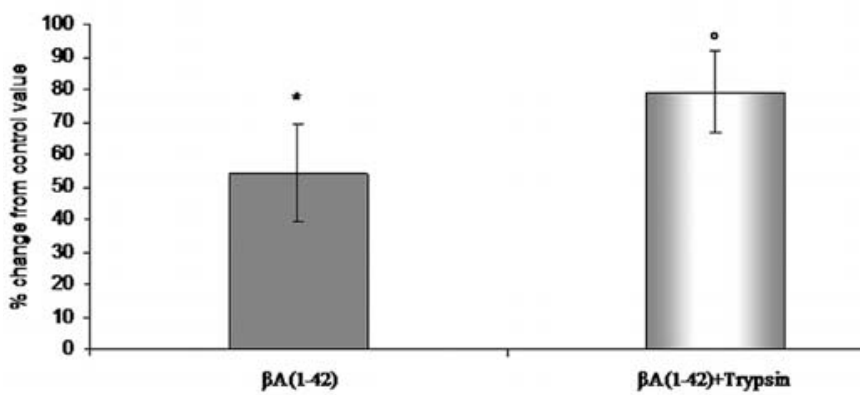

Figure 1. Effects of the $\mathrm{BA}_{(1-42)}$ peptide without or with trypsin pre-treatment on the survival of cultured rat CECs, as measured by trypan blue exclusion assay. Bars are means \pm SEM of four separate experiments. ${ }^{*} \mathrm{p}<0.05$ compared with the control value; ${ }^{\circ} \mathrm{p}<0.05$ compared with $\mathrm{BA}_{(1-42)}$ treatment.

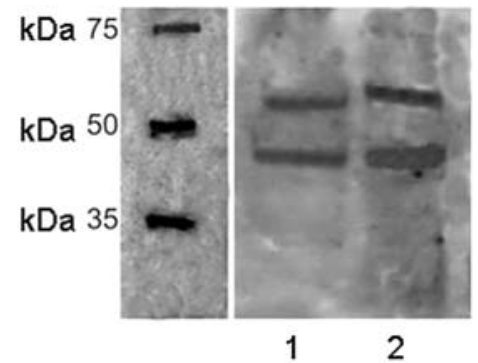

Figure 2. Western blot analysis showing RAGE expression in cultured rat CECs in control cultures (lane 1) and treated cultures (lane 2).

Measurements of nitric oxide production. The NO levels in the culture supernatants were measured by determining the concentration of nitrite using a colorimetric assay kit (Nitrate/Nitrite Colorimetric Assay Kit) based on Griess reaction. Supernatants $(80 \mu \mathrm{l})$ from each culture well (control and treatments) were mixed with $20 \mu \mathrm{l}$ of nitrate reductase for conversion of nitrate to nitrite, followed by $100 \mu \mathrm{l}$ of the Griess reagent ( $1 \%$ sulphanilamide and $0.1 \%$ naphthylenediamine dihydrochloride in $2 \%$ phosphoric acid). The levels of nitrite in the samples were determined by measuring the absorbance of the color product at a $540 \mathrm{~nm}$ wavelength with the Microplate Autoreader EL-13.

Immunocytochemistry. iNOS expression was examined by immunocytochemistry. Cultures were fixed for $10 \mathrm{~min}$ at $4^{\circ} \mathrm{C}$ in ice-cold acetone, rinsed in PBS, and treated with $1 \%$ Triton X-100 in PBS for $5 \mathrm{~min}$ at room temperature followed by the blocking of unspecific sites with $0.5 \%$ BSA in PBS for 15-20 min. Next, cells were incubated with mouse antiNOS2 monoclonal IgG antibody (1:100) for $60 \mathrm{~min}$. Then, cells were incubated with the secondary peroxidase-conjugated anti-rabbit IgG (1:150) for $30 \mathrm{~min}$. Each incubation was followed by 3 washes with PBS. The reaction was developed with the avidin-biotin-amplified immunoperoxidase method, using the Vectastain Elite ABC Kit and Peroxidase Substrate Kit DAB. Finally, samples were stained with hematoxylin. Negative controls were carried out by similarly treating cultures and omitting the primary antibody.

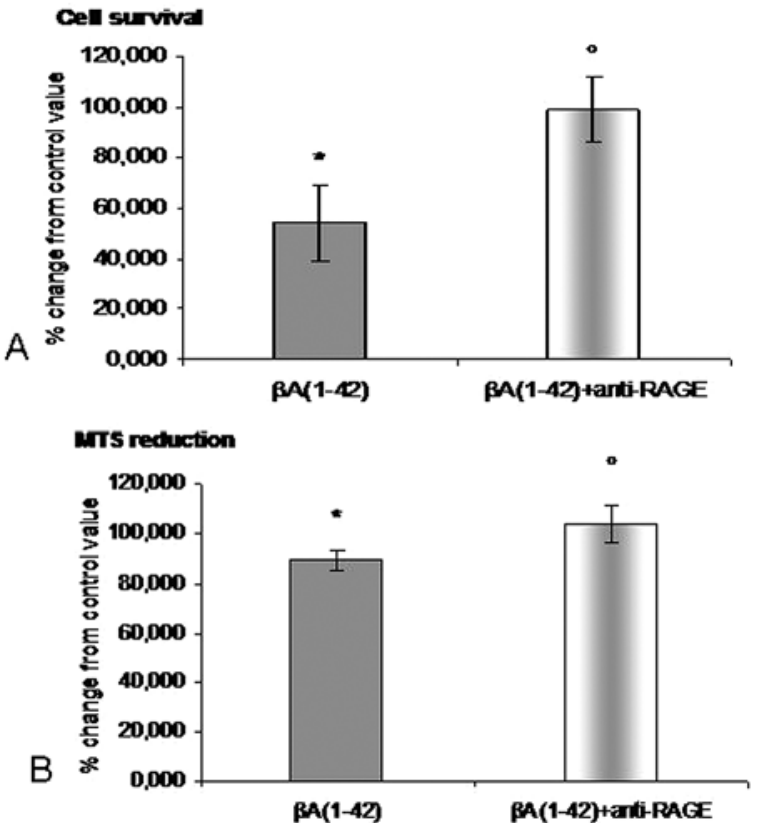

Figure 3. Effects of the $\mathrm{BA}_{(1-42)}$ peptide without or with anti-RAGE pretreatment on rat CEC (A) survival, as measured by trypan blue exclusion assay and (B) redox activity, as measured by MTS assay. Bars are means \pm SEM of four separate experiments. ${ }^{*} \mathrm{p}<0.05$ compared with the control value; ${ }^{\circ} \mathrm{p}<0.05$ compared with $\mathrm{BA}_{(1-42)}$ treatment.

Statistical analysis. Statistical analysis was performed using the SPSS statistical software package. Results were expressed as percent change from control value, and were the mean \pm SEM of four separate experiments. Statistical analysis was performed by ANOVA followed by the t-test of StudentNewman-Keuls as a post-hoc test.

\section{Results}

Trypsin pre-treatment. As previously demonstrated, $\beta \mathrm{A}_{(1-42)}$ treatment induced, after a 6-h incubation period, a significant $(p<0.05)$ decrease in cell survival in respect to the control cultures, as evaluated by trypan blue exclusion. In contrast, trypsin pre-treatment induced a significant $(\mathrm{p}<0.05)$ increase in cell survival compared to the peptide alone incubation (Fig. 1), suggesting that CEC binding sites are likely membrane proteins.

$R A G E$ involvement in mediating $\beta A_{(1-42)}$ effects on CECs. RAGE presence in CEC cultures was evaluated by means of immunoblotting. Western blot assay, performed on cell lysates, detected two bands with molecular sizes of 55 and $45 \mathrm{kDa}$, representing the RAGE intermembranal and C-truncated isoform, respectively. As shown in Fig. 2, both bands were present in $\mathrm{BA}_{(1-42)}$-treated and control samples.

Pre-treatment with anti-RAGE IgG induced a significant $(\mathrm{p}<0.05)$ increase in cell survival (Fig. 3A) and redox activity (Fig. 3B) compared to the peptide alone incubation, as evaluated by trypan blue exclusion and MTS-reduction assay, respectively. CECs, cultured on Matrigel, spread and aligned with each other to form branching anastomosing tubes that gave rise within $24 \mathrm{~h}$ to a meshwork of capillary- 

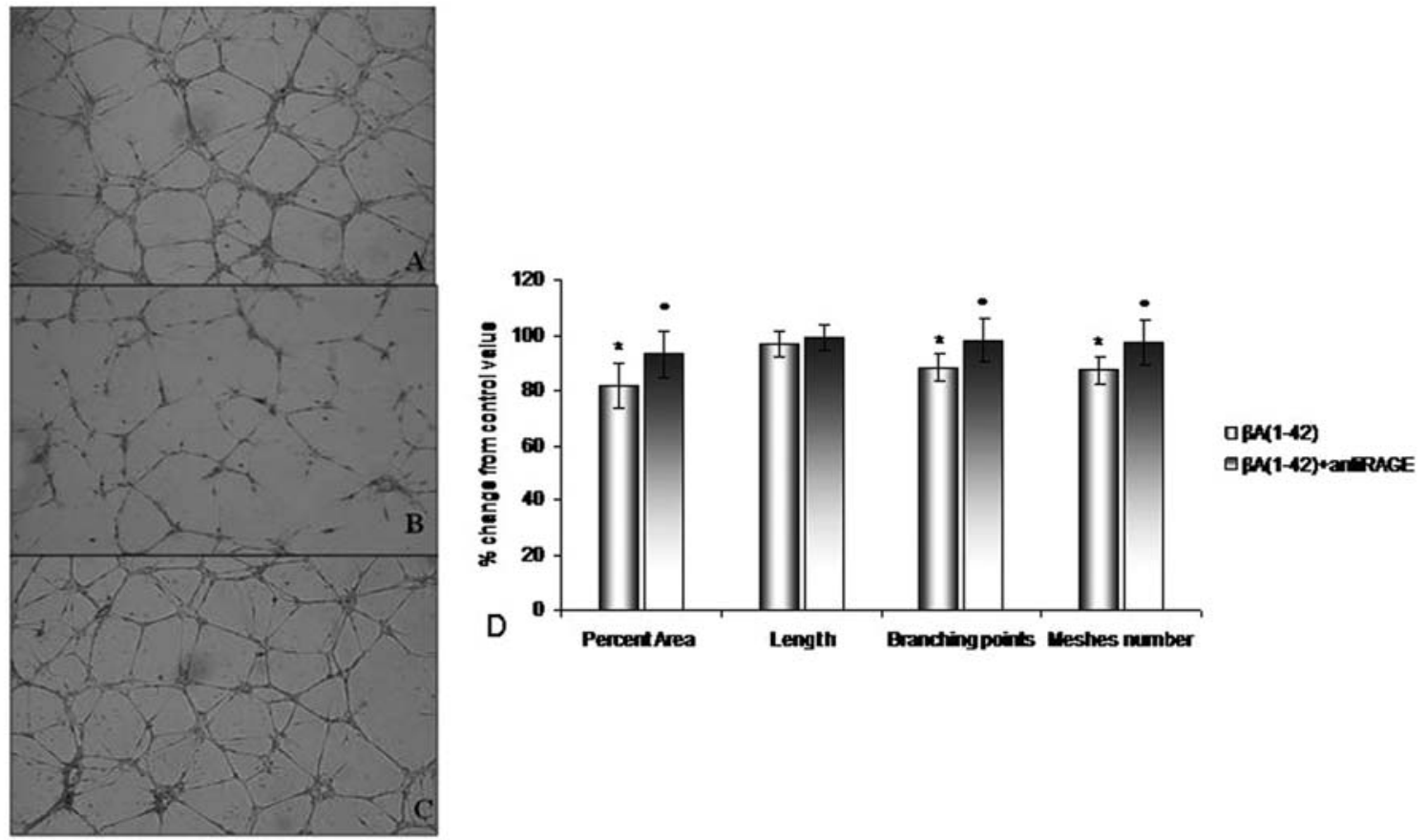

Figure 4. Phase contrast micrographs illustrating the arrangement of rat CECs into a meshwork of capillary-like tubules when cultured on (A) Matrigel for $24 \mathrm{~h}$. (B) $\mathrm{BA}_{(1-42)}$ peptide prevents and (C) anti-RAGE IgG pre-treatment increases the formation of the meshwork (x50). (D) Quantitative analysis of the effects of the $\mathrm{BA}_{(1-42)}$ peptide without or with anti-RAGE pre-treatment on the dimensional [percent area covered by CECs and total length per field (length)] and topological parameters [number of branching points per field (branching) and number of meshes per field (number)] of CEC capillary-like meshwork. Bars are means \pm SEM of four separate experiments. ${ }^{*} \mathrm{p}<0.05$ compared with the control value; ${ }^{\circ}<0.05$ compared with $\beta \mathrm{A}_{(1-42)}$ treatment.

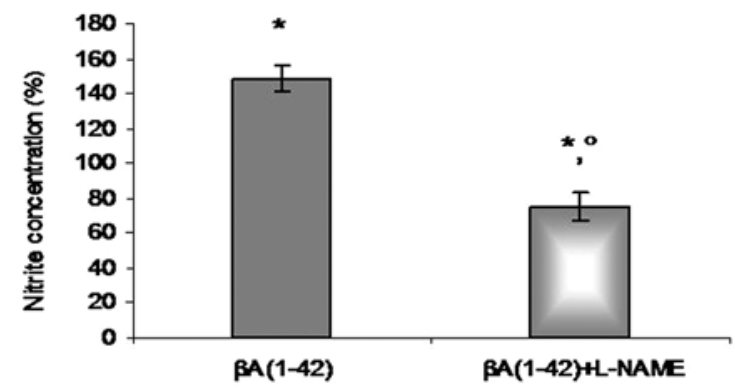

Figure 5. Effects of the $B A_{(1-42)}$ peptide without or with L-NAME cotreatment on nitrite release from CECs. Bars are means \pm SEM of four separate experiments. ${ }^{\mathrm{p}} \mathrm{p}<0.05$ compared with the control value, ${ }^{\circ} \mathrm{p}<0.05$ compared with $\beta \mathrm{A}_{(1-42)}$ treatment.

like structures (Fig. 4A). Incubation with $\beta_{(1-42)}$ prevented network formation (Fig. 4B), while, pre-treatment with antiRAGE inhibited the anti-angiogenic effect of the peptide (Fig. 4C). Image analysis confirmed these observations, showing that the $B \mathrm{~A}_{(1-42)}$ peptide significantly prevented $(\mathrm{p}<0.05)$, with respect to the control, dimensional (percent area covered by CECs) and topological parameters (number of meshes and branching points per field) of the capillarylike network. In contrast, anti-RAGE IgG pre-treatment induced a significant $(\mathrm{p}<0.05)$ increase, with respect to the peptide incubation, of these parameters (Fig. 4D).

$\beta A_{(1-42)}$ activation of the nitrergic system and $R A G E$ involvement. The nitrite levels in the supernatants of the

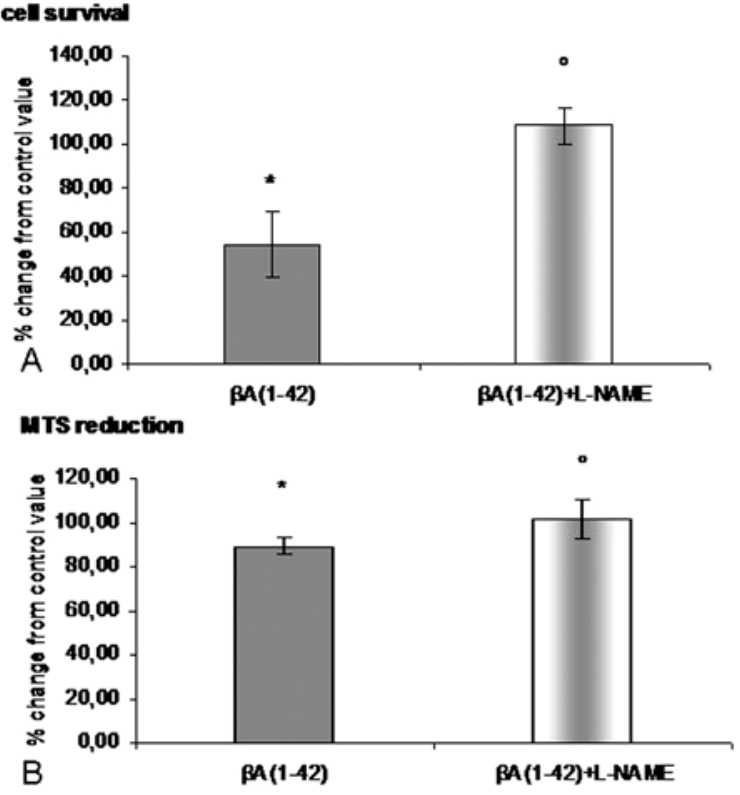

Figure 6. Effects of $B_{(1-42)}$ without or with L-NAME co-treatment on rat CEC (A) survival, as measured by trypan blue exclusion assay and (B) redox activity, as measured by MTS assay. Bars are means \pm SEM of four separate experiments. ${ }^{*} \mathrm{p}<0.05$ compared with the control value; ${ }^{\circ} \mathrm{p}<0.05$ compared with $\beta \mathrm{A}_{(1-42)}$ treatment.

medium in which CECs were incubated for $6 \mathrm{~h}$ with the $\beta \mathrm{A}_{(1-42)}$ peptide alone or $\beta_{(1-42)}$ with L-NAME were quantified. The nitrite levels from CECs significantly $(p<0.05)$ increased 


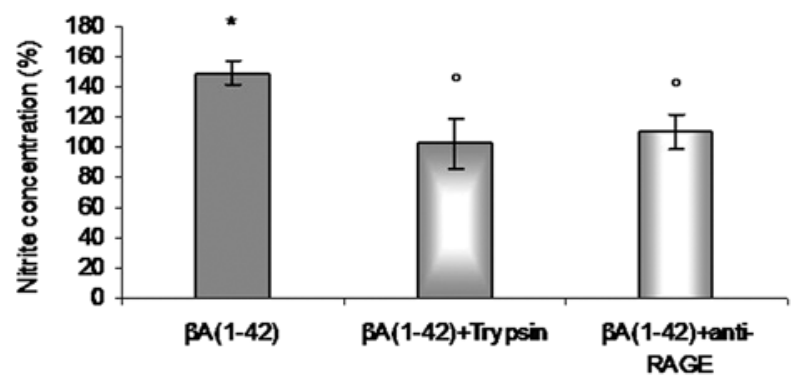

Figure 7. Effects of the $B \mathrm{~A}_{(1-42)}$ peptide without or with trypsin and antiRAGE IgG pre-treatment on nitrite release from CECs. Bars are means \pm SEM of four separate experiments. ${ }^{*} \mathrm{p}<0.05$ compared with the control value, ${ }^{\circ} \mathrm{p}<0.05$ compared with $\mathrm{BA}_{(1-42)}$ treatment.

by nearly 1.5 -fold, compared to the control and significantly $(\mathrm{p}<0.05)$ decreased in respect to the control and to peptide alone treatment with L-NAME co-treatment (Fig. 5). Moreover, co-treatment with L-NAME induced a significant $(\mathrm{p}<0.05)$ increase in cell survival (Fig. 6A) and redox activity (Fig. 6B) compared to the peptide alone incubation, as evaluated by trypan blue exclusion and MTS-reduction assay, respectively.

The nitrite levels in the supernatants of the medium in which CECs were incubated for $6 \mathrm{~h}$ with $\mathrm{BA}_{(1-42)}$ after pretreatment with trypsin solution or with anti-RAGE IgG were evaluated. As shown in Fig. 7, both pre-treatments induced a significant $(\mathrm{p}<0.05)$ decrease in nitrite levels compared to the peptide alone incubation.

Immunoreactivity to inducible nitric oxide synthase (iNOS) of CECs by $\mathrm{BA}_{(1-42)}$ treatment is shown in Fig. 8B, which was suppressed by pre-treatment with anti-RAGE IgG (Fig. 8C).

In all experiments, neither trypsin nor anti-RAGE IgG nor L-NAME per se had any significant effect (data not shown).

\section{Discussion}

It has been already established that the $B A$ peptide, and principally the $B \mathrm{~A}_{(1-42)}$ form, plays a major role in the development and progression of Alzheimer disease (AD), inducing neuronal, astrocyte and cerebral vessel damage (18). At the cerebral vascular endothelial level, it has been demonstrated that $\beta \mathrm{A}$ is able to induce vasoconstriction, blood flow decrease and vasoconstriction resistance consequence increase (25). Moreover, Thomas et al (26) demonstrated that the peptide inhibits endothelial cell replication and angiogenic capability. Historically, it has been proposed that cerebral BA has a neuronal origin; however, growing evidence suggests that the peptide may stem from several sources, one of which may be receptor-mediated transport across the blood-brain barrier (BBB) (27). Amyloid from the systemic circulation could be, hence, a major contributor to the brain amyloid burden in severe AD (28). One cell membrane receptor candidate for $\mathrm{BA}$ linking seems to be the receptor for advanced glycosylation-end products, RAGE, which is expressed in numerous cellular types such as neurons, microglia and endothelial cells. It has been shown that RAGE binds $B A$ and

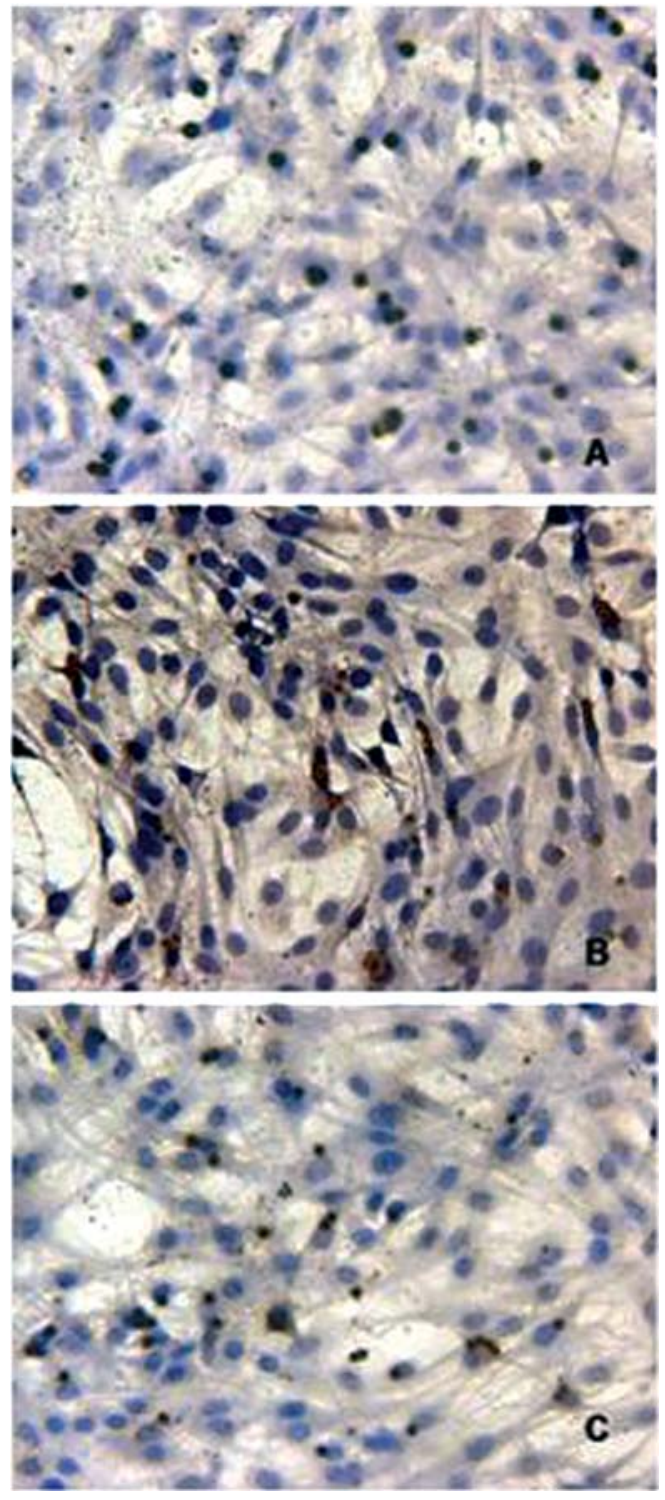

Figure 8. Immunocytochemical assay for iNOS in (A) control CEC culture, (B) after $\beta_{(1-42)}$ treatment without or (C) with anti-RAGE IgG pre-treatment (x250).

mediates pathophysiologically relevant cellular responses $(29,30)$, such as $\beta A$ transport from blood to brain (28). It has been hypothesized that, in pathological conditions such as $\mathrm{AD}, \mathrm{RAGE}$ could act as a co-factor able to increase $B A$ brain levels, with consequent cellular dysfunction, stress oxidative induction, loss of cellular vitality and apoptosis (31). Hence, the interaction of $\mathrm{BA}$ with this membrane receptor could be important in the evolution of cellular dysfunction which is prominent in $\mathrm{AD}$ pathology.

To ascertain whether the potential biological effects of BA on microvascular endothelium are, almost in part, mediated by a proteic membrane receptor, RAGE in particular, we performed a series of experiments on in vitro rat cerebromicrovascular endothelial cell cultures.

First, we observed that trypsin digestion pre-treatment inhibited the toxic effects of BA on CECs, indicating that endothelial cell binding sites are likely membrane proteins, as suggested by Bateman et al (32) on neuronal cells. 
Western blot analysis confirmed the presence of RAGE on CECs, not only the full-length type but also the C-truncated isoform, the soluble isoform, either in control and treated cultures.

In order to examine whether RAGE specifically blocks $\beta_{(1-42)}$ peptide cytotoxicity on CECs, we used antibody antiRAGE IgG pre-treatment. We found that anti-RAGE IgG pre-treatment markedly increased cerebromicrovascular endothelial cell survival, viability and angiogenic capability, confirming the role of RAGE in playing a part in $\mathrm{BA}_{(1-42)^{-}}$ induced toxic effects.

In Alzheimer disease (AD), nitric oxide (NO) has been implicated in the neurodegeneration process and neuronal cell death, through NO-mediated neurotoxicity (33). Multiple $\mathrm{AD}$ pathological factors have been, in fact, shown to affect nitric oxide synthase (NOS) expression, suggesting that NO involvement appears to be significantly related to oxidative damage in this pathology. Several studies have shown that BA stimulates microglial and astrocytic NO production probably throughout the activation of inflammatory mechanisms by means of an iNOS-mediated release $(18,34,35)$. Moreover, similar mechanisms, iNOS activation and consequent NO high levels of induction, seem to be operative in brain microvessels isolated from $\mathrm{AD}$ patients which are amyloid burdened (36).

Our data showed that exposure of in vitro CEC cultures to the $\mathrm{BA}_{(1-42)}$ peptide increased the extracellular nitrite levels, and the presence of L-NAME, a nitric oxide synthase inhibitor, enhanced CEC survival and viability, suggesting that NO plays a role in the $\mathrm{BA}_{(1-42)}$-induced toxicity on cerebral endothelial cells. Furthermore, our immunocytochemical data support the hypothesis that $\mathrm{BA}_{(1-42)}$ in CECs induces expression of the inducible isoform of nitric oxide synthase (iNOS), typically synthesized in response to immune/ inflammatory stimuli. Previous studies have shown that iNOS levels are increased in neurons and glial cells in AD (35). Moreover, Luth et al (14) demonstrated that NOS-reactive astrocytes in $\mathrm{AD}$ were associated with primitive, but not with 'burned out' plaques suggesting that this tissue response could be restricted to early stages of plaque formation (14). Our data seem to be consistent with these results demonstrating that $\mathrm{BA}_{(1-42)}$ induces iNOS expression in CEC cultures.

Moreover, our data suggest that RAGE mediates the activation of the $B \mathrm{~A}_{(1-42)}$-induced nitrergic system on CECs. In fact, with trypsin pre-treatment and by blocking the interaction to RAGE, we observed significant decreased levels of NO and iNOS immunoreactivity suppression. Currently, to our knowledge, there are no literature data related to RAGE involvement in BA nitrergic system activation; however, it has been demonstrated that RAGE linkage with other ligands, as advanced glycation-end products (AGE), stimulated iNOS expression in mouse macrophages (37), in murine endothelial cells (38), and in murine macrophages (39). AGE stimulation led to nitrite accumulation and iNOS protein expression, which were partially downregulated by preincubation with anti-RAGE antibody, suggesting the role of RAGE in AGE-induced nitrosative stress activation $(39,40)$.

In conclusion, our data suggest RAGE involvement, at least partly, in mediating $\mathrm{BA}_{(1-42)}$ effects on CECs. In particular, the decrease of in vitro cell viability and functionality and nitrosative stress activation was inhibited by preventing $B A_{(1-42)}$-RAGE interaction. These results suggest the potential utility of specifically blocking this receptor as a future therapeutic approach to decreasing $B A$ transport from blood to brain.

\section{Acknowledgements}

The authors are indebted to Dr Diego Guidolin, Department of Human Anatomy and Physiology, University of Padua, for his image analysis program for the Matrigel assay. This work was supported by a grant of the 'Regione del Veneto, Giunta Regionale-Ricerca Sanitaria Finalizzata 2004-Venezia-Italy' with the collaboration of 'ULSS 13-Mirano-Venezia-Italy'.

\section{References}

1. Farkas E and Luiten PGM: Cerebral microvascular pathology in aging and Alzheimer's disease. Prog Neurobiol 64: 575-611, 2001.

2. Kumar-Singh S, Pirici D, McGowan E, Serneels S, Ceuterick C, Hardy J, Duff K, Dickson D and Van Broeckhoven C: Dense core plaques in Tg2576 and PSAPP mouse models of Alzheimer's disease are centered on vessel walls. Am J Pathol 167: 527-543, 2005.

3. Van Broeck B, Van Broeckhoven C and Kumar-Singh S: Current insights into molecular mechanisms of Alzheimer disease and their implications for therapeutic approaches. Neurodegener Dis 4: 349-365, 2007.

4. Humpel C and Marksteiner J: Cerebrovascular damage as a cause for Alzheimer's disease. Curr Neurovasc Res 2: 341-347, 2005.

5. Deane R and Zlokovic BV: Role of the blood-brain barrier in the pathogenesis of Alzheimer's disease. Curr Alzheimer Res 4: 191-197, 2007.

6. Zlokovic BV: Clearing amyloid through the blood-brain barrier. J Neurochem 89: 807-811, 2004.

7. Begley DJ and Brightman MW: Structural and functional aspects of the blood-brain barrier. Prog Drug Res 61: 39-78, 2003.

8. Chen X, Walker DG, Schmidt AM, Arancio O, Lue LF and Yan SD: RAGE: a potential target for Abeta-mediated cellular perturbation in Alzheimer's disease. Curr Mol Med 7: 735-742, 2007.

9. Lue LF, Yan SD, Stern DM and Walker DG: Preventing activation of receptor for advanced glycation endproducts in Alzheimer's disease. Curr Drug Targets CNS Neurol Disord 4: 249-266, 2005.

10. Munoz FJ, Opazo C, Gil-Gomez G, Tapia G, Fernandez V, Valverde MA and Inestrosa NC: Vitamin E but not 17betaestradiol protects against vascular toxicity induced by betaamyloid wild type and the Dutch amyloid variant. J Neurosci 22: 3081-3089, 2002

11. Folin M, Baiguera S, Fioravanzo L, Conconi MT, Grandi C, Nussdorfer GG and Parnigotto PP: Caspase- 8 activation and oxidative stress are involved in the cytotoxic effect of $\beta$-amyloid on rat brain microvascular endothelial cells. Int J Mol Med 17: 431-435, 2006.

12. Neuroinflammation Working Group: Inflammation and Alzheimer's disease. Neurobiol Aging 21: 383-421, 2000.

13. Smith MA, Richey Harris PL, Sayre LM, Beckman JS and Perry G: Widespread peroxynitrite-mediated damage in Alzheimer's disease. J Neurosci 17: 2653-2657, 1997.

14. Luth HJ, Holzer M, Gartner U, Staufenbiel M and Arendt T: Expression of endothelial and inducible NOS-isoforms is increased in Alzheimer's disease, in APP23 transgenic mice and after experimental brain lesion in rat: evidence for an induction by amyloid pathology. Brain Res 913: 57-67, 2001.

15. Luth HJ, Munch G and Arendt T: Aberrant expression of NOS isoforms in Alzheimer's disease is structurally related to nitrotyrosine formation. Brain Res 953: 135-143, 2002.

16. Verdier Y, Zarándi M and Penke B: Amyloid beta-peptide interactions with neuronal and glial cell plasma membrane: binding sites and implications for Alzheimer's disease. J Pept Sci 10: 229-248, 2004 
17. Ramírez G, Rey S and von Bernhardi R: Proinflammatory stimuli are needed for induction of microglial cell-mediated AbetaPP $\{244-C\}$ and Abeta-neurotoxicity in hippocampal cultures. J Alzheimers Dis 15: 45-59, 2008.

18. Akama KT, Albanese C, Pestell RG and Van Eldik LJ: Amyloid beta-peptide stimulates nitric oxide production in astrocytes through an NFkappaB-dependent mechanism. Proc Natl Acad Sci USA 95: 5795-5800, 1998 .

19. Koh SH, Kim SH, Kwon H, Park Y, Kim KS, Song CW, Kim J Kim MH, Yu HJ, Henkel JS and Jung HK: Epigallocatechin gallate protects nerve growth factor differentiated PC12 cells from oxidative-radical-stress-induced apoptosis through its effect on phosphoinositide 3-kinase/Akt and glycogen synthase kinase-3. Brain Res Mol Brain Res 118: 72-81, 2003.

20. Folin M, Baiguera S, Tommasini M, Guidolin D, Conconi MT, De Carlo E, Nussdorfer GG and Parnigotto PP: Effects of ß-amyloid on rat neuromicrovascular endothelial cells cultured in vitro. Int J Mol Med 15: 929-935, 2005.

21. Abbot NJ, Hughes CCW, Revest PA and Greenwood J: Development and characterization of rat brain capillary endothelial culture: towards an in vitro blood-brain barrier. J Cell Sci 103: 23-27, 1992.

22. Conconi MT, Lora S, Baiguera S, Boscolo E, Folin M, Scienza R, Rebuffat P, Parnigotto PP and Nussdorfer GG: In vitro culture of rat neuromicrovascular endothelial cells on polymeric scaffolds. J Biomed Mat Res 71: 669-674, 2004

23. Baiguera S, Conconi MT, Guidolin D, Mazzocchi G, Malendowicz LK, Parnigotto PP, Nussdorfer GG and Ribatti D: Ghrelin inhibits in vitro angiogenic activity of rat brain microvascular endothelial cells. Int J Mol Med 14: 849-854, 2004.

24. Guidolin D, Vacca A, Nussdorfer GG and Ribatti D: A new image analysis method based on topological and fractal parameters to evaluate the angiostatic activity of docetaxel by using the Matrigel assay in vitro. Microvasc Res 67: 117-124, 2004.

25. Suo Z, Fang C, Crawford F and Mullan M. Superoxide free radical and intracellular calcium mediate $A B(1-42)$ induced endothelial toxicity. Brain Res 762: 144-152, 1997.

26. Thomas T, McLendon C, Sutton ET and Thomas G: Cerebrovascular endothelial dysfunction mediated by beta-amyloid. Neuroreport 8: 1387-1391, 1997.

27. Poduslo JF, Curran GL, Sanyal B and Selkoe DJ: Receptormediated transport of human amyloid beta-protein 1-40 and 142 at the blood-brain barrier. Neurobiol Dis 6: 190-199, 1999.

28. Donahue JE, Flaherty SL, Johanson CE, Duncan JA III, Silverberg GD, Miller MC, Tavares R, Yang W, Wu Q, Sabo E, Hovanesian V and Stopa EG: RAGE, LRP-1, and amyloid-beta protein in Alzheimer's disease. Acta Neuropathol 112: 405-415, 2006.
29. Yan SD, Zhu H, Zhu A, Golabek A, Du H, Roher A, Yu J, Soto C, Schmidt AM, Stern D and Kindy M: Receptor-dependent cell stress and amyloid accumulation in systemic amyloidosis. Nat Med 6: 643-651, 2000.

30. Lue LF, Walker DG, Brachova L, Beach TG, Rogers J, Schmidt AM, Stern DM and Yan SD: Involvement of microglial receptor for advanced glycation endproducts (RAGE) in Alzheimer's disease: identification of a cellular activation mechanism. Exp Neurol 171: 29-45, 2001.

31. Schmidt AM, Yan SD, Yan SF and Stern DM: The biology of the receptor for advanced glycation and products and its ligands. Biochim Biophys Acta 1498: 99-111, 2000.

32. Bateman DA, McLaurin J and Chakrabartty A: Requirement of aggregation propensity of Alzheimer amyloid peptides for neuronal cell surface binding. BMC Neurosci 8: 29-41, 2007.

33.Law A, Gauthier S and Quirion R: Say NO to Alzheimer's disease: the putative links between nitric oxide and dementia of the Alzheimer's type. Brain Res Brain Res Rev 35: 73-96, 2001.

34. Goodwin JL, Kehrli ME Jr and Uemura E: Integrin Mac-1 and beta-amyloid in microglial release of nitric oxide. Brain Res 768: 279-286, 1997.

35. Wallace MN, Geddes JG, Farquhar DA and Masson MR: Nitric oxide synthase in reactive astrocytes adjacent to beta-amyloid plaques. Exp Neurol 144: 266-272, 1997.

36. Dorheim MA, Tracey WR, Pollock JS and Grammas P: Nitric oxide synthase activity is elevated in brain microvessels in Alzheimer's disease. Biochem Biophys Res Commun 205: 659-665, 1997.

37. Rojas A, Caveda L, Romay C, López E, Valdés S, Padrón J, Glaría L, Martínez O and Delgado R: Effect of advanced glycosylation end products on the induction of nitric oxide synthase in murine macrophages. Biochem Biophys Res Commun 225: 358-362, 1996

38. Amore A, Cirina P, Mitola S, Peruzzi L, Gianoglio B, Rabbone I, Sacchetti C, Cerutti F, Grillo C and Coppo R: Nonenzymatically glycated albumin (Amadori adducts) enhances nitric oxide synthase activity and gene expression in endothelial cells. Kidney Int 51: 27-35, 1997.

39. Sumi D and Ignarro LJ: Regulation of inducible nitric oxide synthase expression in advanced glycation end productstimulated raw 264.7 cells: the role of heme oxygenase- 1 and endogenous nitric oxide. Diabetes 53: 1841-1850, 2004.

40. Chang P-C, Chen T-H, Chang C-J, Hou C-C, Chan P and Lee H-M: Advanced glycosylation end products induce inducible nitric oxide synthase (iNOS) expression via a p38 MAPK-dependent pathway. Kidney Int 65: 1664-1675, 2004. 